\title{
Predicting frequent asthma exacerbations using blood eosinophil count and other patient data routinely available in clinical practice
}

This article was published in the following Dove Press journal:

Journal of Asthma and Allergy

7 January 2016

Number of times this article has been viewed

\author{
David Price ${ }^{1,2}$ \\ Andrew MWilson ${ }^{3}$ \\ Alison Chisholm ${ }^{4}$ \\ Anna Rigazio ${ }^{2}$ \\ Anne Burden ${ }^{2}$ \\ Michael Thomas ${ }^{5}$ \\ Christine King ${ }^{2}$ \\ 'Centre for Academic Primary Care, \\ The Institute of Applied Health \\ Sciences, University of Aberdeen, \\ Aberdeen, ${ }^{2}$ Research in Real-Life, \\ Cambridge, ${ }^{3}$ Norwich Medical School, \\ University of East Anglia, Norwich, \\ ${ }^{4}$ Respiratory Effectiveness Group, \\ Cambridge, ${ }^{5}$ Primary Medical \\ Care, University of Southampton, \\ Southampton, UK
}

Purpose: Acute, severe asthma exacerbations can be difficult to predict and thus prevent. Patients who have frequent exacerbations are of particular concern. Practical exacerbation predictors are needed for these patients in the primary-care setting.

Patients and methods: Medical records of 130,547 asthma patients aged 12-80 years from the UK Optimum Patient Care Research Database and Clinical Practice Research Datalink, 1990-2013, were examined for 1 year before (baseline) and 1 year after (outcome) their most recent blood eosinophil count. Baseline variables predictive $(P<0.05)$ of exacerbation in the outcome year were compared between patients who had two or more exacerbations and those who had no exacerbation or only one exacerbation, using uni- and multivariable logistic regression models. Exacerbation was defined as asthma-related hospital attendance/admission (emergency or inpatient) or acute oral corticosteroid (OCS) course.

Results: Blood eosinophil count $>400 / \mu \mathrm{L}$ (versus $\leq 400 / \mu \mathrm{L}$ ) increased the likelihood of two or more exacerbations $>1.4$-fold (odds ratio [OR]: 1.48 (95\% confidence interval [CI]: 1.39, 1.58); $P<0.001$ ). Variables that significantly increased the odds by up to 1.4 -fold included increasing age (per year), female gender (versus male), being overweight or obese (versus normal body mass index), being a smoker (versus nonsmoker), having anxiety/depression, diabetes, eczema, gastroesophageal reflux disease, or rhinitis, and prescription for acetaminophen or nonsteroidal anti-inflammatory drugs. Compared with treatment at British Thoracic Society step 2 (daily controller \pm reliever), treatment at step 0 (none) or 1 (as-needed reliever) increased the odds by 1.2- and 1.6-fold, respectively, and treatment at step 3, 4, or 5 increased the odds by 1.3-, 1.9-, or 3.1-fold, respectively (all $P<0.05$ ). Acute OCS use was the single best predictor of two or more exacerbations. Even one course increased the odds by more than threefold (OR: 3.75 [95\% CI: 3.50, 4.01]; $P<0.001$ ), and three or more courses increased the odds by $>25$-fold (OR: 25.7 [95\% CI: 23.9, 27.6]; $P<0.001$ ).

Conclusion: Blood eosinophil count and several other variables routinely available in patient records may be used to predict frequent asthma exacerbations.

Keywords: exacerbator, risk, multiple, hospitalization

\section{Introduction}

Acute, severe exacerbations of asthma are characterized by a rapid worsening of asthma symptoms, necessitating an urgent hospital visit and/or a course of systemic corticosteroids. ${ }^{1}$ Severe exacerbations are a well-recognized feature of asthma, yet they remain difficult to predict and thus prevent in many patients. Those who have multiple exacerbations in a year, sometimes termed frequent exacerbators ${ }^{2}$ or exacerbation-prone patients, ${ }^{3,4}$ are of particular concern, both for the patients themselves and for the added burden they place on health care systems. ${ }^{3,5}$
Correspondence: David Price Centre for Academic Primary Care, The Institute of Applied Health Sciences, University of Aberdeen, Polwarth Building, Foresterhill, Aberdeen AB25 2ZD, UK $\mathrm{Tel}+44 \mathrm{I} 224554588$

Fax +44I224550683

Email david@respiratoryresearch.org 
The current recommendations for asthma management and prevention by the Global Initiative for Asthma (GINA) emphasize the importance of taking steps to reduce the patient's exacerbation risk while also ensuring adequate symptom control. ${ }^{6}$ The recommendations review a number of specific exacerbation risk factors which form the basis of the strategies advised for reducing the patient's exacerbation risk. Even so, more studies focused specifically on the risks for frequent exacerbations are needed. Whether or not they represent a distinct asthma phenotype, ${ }^{2,4}$ patients at risk for frequent exacerbations are in particular need of identification and targeted exacerbation risk management. ${ }^{3}$

A handful of cohort studies have investigated the specific risks for multiple exacerbations compared with patients who had, at most, one exacerbation in the same period. The following factors were significantly associated with frequent exacerbations: worse symptom control; $; 2,7$ greater number of exacerbations in the past year ${ }^{8,9}$ and exacerbations that were more severe (hospitalization, arrival by ambulance), ${ }^{9,10}$ being a smoker, ${ }^{2,11}$ having certain comorbidities, such as psychosocial disorder, ${ }^{7,9}$ chronic sinusitis, ${ }^{9,10}$ recurrent respiratory infections, ${ }^{9}$ and gastroesophageal reflux disease; ${ }^{9}$ intolerance of nonsteroidal anti-inflammatory drugs (NSAIDs), ${ }^{10}$ greater use of inhaled corticosteroids (ICSs) and oral corticosteroids $(\mathrm{OCSs}) ;{ }^{2,10}$ and having higher sputum ${ }^{2}$ or blood ${ }^{12}$ eosinophil counts, higher fractional exhaled nitric oxide (FeNO) values, ${ }^{2}$ and poorer lung function., ${ }^{2,10}$

However, those studies were limited to specific patient populations (eg, emergency department attendees, ${ }^{7}$ adult nonsmokers, ${ }^{9,10}$ severe or difficult-to-treat asthma ${ }^{2,8,9}$ ), to $<100$ patients with multiple exacerbations, ${ }^{2,9-11}$ or to single indices (eg, blood eosinophil count ${ }^{12}$ ), and the definition of an exacerbation differed among studies. Characterization of patients at increased risk for frequent acute, severe exacerbations and identification of specific predictors are still needed for the general asthma population.

Furthermore, some of the reported exacerbation predictors, such as sputum eosinophil count and FeNO (both indicators of bronchial eosinophil activation ${ }^{2}$ ), may not be feasible across broad populations. Eosinophilic asthma is a common asthma phenotype,,$^{13}$ and elevated sputum or blood eosinophil counts have been associated with increased exacerbation risk,,$^{2,12,14-20}$ so assessment of eosinophil recruitment/ activation is important in the clinical evaluation of exacerbation risk. ${ }^{21}$ However, not only is the assessment of bronchial eosinophilia impractical outside of tertiary care and research facilities, but there is also some evidence that systemic eosinophilia may be a better predictor of severe exacerbations..$^{16,21}$ Thus, blood eosinophil count may be the more useful, as well as the more practical, clinical index of eosinophil recruitment and consequent exacerbation risk.

In this study, we investigated the value of blood eosinophil count and other routinely collected data - information already available in the electronic medical records of most UK asthma patients or easily obtainable in general practice - for predicting multiple exacerbations in the next year. We hypothesized that data routinely collected during clinic visits may be used to identify asthma patients at significant risk for two or more exacerbations. By identifying specific risk factors and determining the predictive value of each within a multivariable model, our goal was to generate a weighted list of exacerbation predictors that would enable the physician to design an individualized management plan aimed at decreasing the patient's exacerbation risk.

\section{Patients and methods Study patients}

We conducted a historical study of UK asthma patients treated in clinical practice, using data obtained from two large, anonymized patient databases: the Optimum Patient Care Research Database (OPCRD; http://www.optimumpatientcare.org) and Clinical Practice Research Datalink (CPRD; http://www.cprd. $\underline{\text { com). }}$. Research use of the OPCRD was performed in compliance with all applicable local and international laws and regulations, including The International Council for Harmonisation of Technical Requirements for Pharmaceuticals for Human Use E6 guidelines for Good Clinical Practices. Research use of CPRD was approved by the UK National Information Governance Board Ethics and Confidentiality Committee.

Data were examined for the period between August 1990 and February 2013. Figure 1 summarizes the patient selection process. The final study group consisted of patients with a physician-recorded diagnosis of asthma but no other chronic respiratory disease, at least one valid blood eosinophil count (see the following paragraph), 1 full year of data on each side of the index blood eosinophil count, and aged between 12 years and 80 years at the index date.

A valid blood eosinophil count constituted a numerical value recorded as, or able to be converted to, cells $/ \mu \mathrm{L}$. To avoid extreme outliers, patients with blood eosinophil counts $>5,000 / \mu \mathrm{L}$ were excluded. When a patient had multiple valid blood eosinophil counts, the most recent count which allowed the collection of 1 full year of data before and after was selected as the index count.

Because hospital attendances and admissions tend to be underreported in these clinical practice databases, we also examined a subset of the study group for whom Hospital Episode Statistics (HES) data were available from the UK 


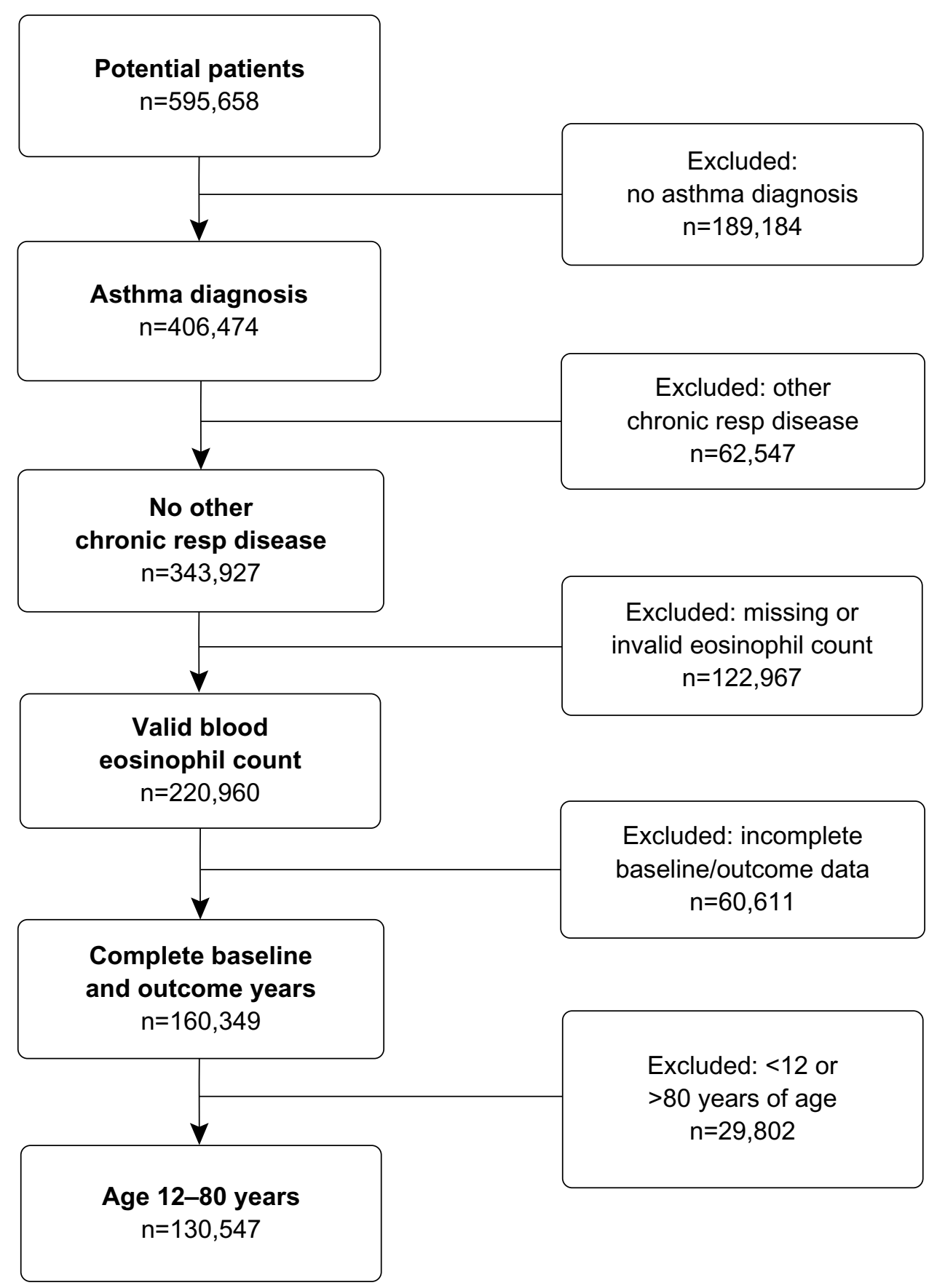

Figure I CONSORT diagram of the patient selection process. Abbreviation: resp, respiratory.

National Health Service regarding inpatient admissions for asthma during the study period. (Further details of the full study group and the HES subset are provided in the Supplementary materials).

\section{Study design}

Our main objective was to identify and weight the routine clinical indices that were predictive of multiple (2+) severe asthma exacerbations in the next year. To that end, we examined the medical record of each study patient for the year before (baseline) and the year after (outcome) the date of the index blood eosinophil count. The baseline year was used to characterize the study population and identify variables that may be predictive of multiple exacerbations in the outcome year (Figure S1).

\section{Outcomes and variables}

The primary outcome of interest was the occurrence of acute, severe exacerbation (hereafter, simply called an 
exacerbation), as defined by the American Thoracic Society and European Respiratory Society ${ }^{1}$ : asthma-related hospital attendance/admission (either Accident and Emergency department [A\&E] or inpatient) or acute OCS course. Any such events within a 2 -week window were counted as a single exacerbation.

In the HES subset, the outcome measure was the occurrence of hospital inpatient admission for asthma as recorded in the HES database (hereafter, simply called hospitalization).

The key baseline variables examined are summarized in Table 1; a complete list is provided in Table S1. Comorbid rhinitis (diagnosis of rhinitis at any time or prescription for rhinitis nasal spray during baseline year) was used as a proxy for atopy. The variable "treatment step" was based on the British Thoracic Society and Scottish Intercollegiate Guidelines Network (BTS-SIGN) recommendations for asthma in adults and children $>12$ years of age that were current at the time of data extraction. ${ }^{22}$ All short-acting $\beta_{2}$ agonist (SABA) dosages are reported as salbutamol equivalents: terbutaline dosages were divided by 2.5 to yield the salbutamol-equivalent dosage. All ICS dosages are reported as fluticasone propionate (FP) equivalents: large-particle beclomethasone dipropionate (BDP) and budesonide dosages were divided by 2 to yield the FP-equivalent dosage; extrafine-particle BDP and ciclesonide dosages were considered equivalent to FP dosages for this study. (Further details of the study design and variables examined are provided in the Supplementary materials).

\section{Statistical analysis}

All analyses were conducted using SPSS Statistics version 21 (IBM Corp, Armonk, NY, USA), SAS version 9.3 (SAS Institute Inc., Cary, NC, USA), and Microsoft Excel 2013 (Microsoft Corp, Redmond, WA, USA). We defined statistically significant results as $P<0.05$. Normally distributed data are reported as means with their standard deviations; data not normally distributed are reported as medians with their interquartile ranges (defined by their 25 th and 75 th percentiles). Odds ratios (ORs) are reported with their $95 \%$ confidence intervals (CIs).

Because some patients may have, at most, one exacerbation in a year while others may have multiple, we compared patients who had no exacerbations or only one with those who had two or more ( $0 / 1$ versus $2+$ exacerbations). After generating descriptive statistics, correlations between potentially confounding baseline variables were assessed using Spearman correlation coefficients. Relationships with rank correlation coefficients $>0.30$ were considered, in conjunction with
Table I Key baseline variables examined as predictors of multiple exacerbations

\begin{tabular}{|c|c|}
\hline Variable & Description \\
\hline Age & In years \\
\hline Gender & Male or female \\
\hline BMI & $\begin{array}{l}\text { In } \mathrm{kg} / \mathrm{m}^{2} \text {; also categorized as underweight } \\
(<18.5) \text {, normal }(18.5-24.9) \text {, overweight } \\
(25-29.9) \text {, or obese }(\geq 30)\end{array}$ \\
\hline Smoking status & Nonsmoker, smoker, or ex-smoker \\
\hline$\%$ predicted PEF & $\begin{array}{l}\text { PEF, expressed as percentage of } \\
\text { predicted normal }\end{array}$ \\
\hline Blood eosinophil count & $\begin{array}{l}\text { Actual value (cells } / \mu \mathrm{L} \text { ); also categorized } \\
\text { as } \leq 400 / \mu \mathrm{L} \text { or }>400 / \mu \mathrm{L}\end{array}$ \\
\hline Comorbidities & $\begin{array}{l}\text { Anaphylaxis (history), anxiety/depression, } \\
\text { diabetes (type I or II), eczema, GERD, } \\
\text { heart failure, ischemic heart disease, } \\
\text { psoriasis, rhinitis }\end{array}$ \\
\hline Comedications & $\begin{array}{l}\text { Prescription for acetaminophen or } \\
\text { NSAIDs }\end{array}$ \\
\hline \multicolumn{2}{|l|}{ Treatment step ${ }^{a}$} \\
\hline Step 0 & No treatment \\
\hline Step I & Inhaled SABA as needed \\
\hline Step 2 & Add ICS or LTRA \\
\hline Step 3 & $\begin{array}{l}\text { Add LABA to ICS or use high-dose ICS } \\
\text { ( } \geq 400 \mu \mathrm{g} / \text { day FP equivalent) }\end{array}$ \\
\hline Step 4 & $\begin{array}{l}\text { Add LTRA/Theo to }[I C S+L A B A] \text { or add } \\
\text { LABA/LTRA/Theo to high-dose ICS }\end{array}$ \\
\hline Step 5 & Add OCS \\
\hline Average SABA dosage & $\begin{array}{l}\text { In } \mu g / \text { day, salbutamol equivalents } \\
\text { (explained in text) }\end{array}$ \\
\hline Average ICS dosage & $\begin{array}{l}\text { In } \mu g / \text { day, FP equivalents } \\
\text { (explained in text) }\end{array}$ \\
\hline GP consults for LRTI & $\begin{array}{l}\text { Consultations that resulted in antibiotic } \\
\text { prescription (included to capture asthma } \\
\text { events that may have been misclassified } \\
\text { as LRTI) }\end{array}$ \\
\hline Acute OCS courses & Number of acute courses \\
\hline $\begin{array}{l}\text { Hospital attendance/ } \\
\text { admission }\end{array}$ & $\begin{array}{l}\text { Any asthma-related } \mathrm{A} \& \mathrm{E} \text {, inpatient, or } \\
\text { outpatient attendance/admission }\end{array}$ \\
\hline Exacerbations & $\begin{array}{l}\text { Occurrence of asthma-related hospital } \\
\text { A\&E attendance, inpatient admission, or } \\
\text { acute OCS course }\end{array}$ \\
\hline
\end{tabular}

Notes: aBased on British Thoracic Society recommendations (20II) for adults and children > 12 years; ${ }^{22}$ bany with a Lower Respiratory code (Asthma or LRTI code). Abbreviations: A\&E, Accident and Emergency department; BMI, body mass index; FP, fluticasone propionate; GERD, gastroesophageal reflux disease; GP, general practitioner; ICS, inhaled corticosteroid; LABA, long-acting $\beta_{2}$ agonist; LRTI, lower respiratory tract infection; LTRA, leukotriene receptor antagonist; NSAIDs, nonsteroidal anti-inflammatory drugs; OCS, oral corticosteroid; PEF, peak expiratory flow; SABA, short-acting $\beta_{2}$ agonist; Theo, theophylline.

clinical interpretation, to identify pairs of variables that may present collinearity issues at the modeling stage.

We began with univariable logistic regression models to identify baseline variables that were predictive of multiple exacerbations in the outcome year. The dichotomous variable ( $0 / 1$ versus $2+$ exacerbations) was used as the dependent variable, with each baseline measure as an 
explanatory variable. The baseline variables that showed a significant association with two or more exacerbations in the outcome year were entered into a multivariable model, which was stepwise reduced to produce a final list of noncollinear predictors of two or more exacerbations.

With the clinically relevant variables that were found to be collinear, we repeated the multivariable model, substituting the second variable of the pair for the first (eg, average daily SABA dosage for treatment step). Those results are reported separately. As not all patients had recorded baseline values for peak expiratory flow (PEF), we repeated the analyses for the subset of patients with PEF data (excluding the patients missing PEF data) in order to determine the value of PEF for predicting multiple exacerbations. Those results are also reported separately.

In the HES subset, separate uni- and multivariable analyses were conducted to identify baseline variables that were predictive of at least one hospitalization, using 0 versus $1+$ as the dependent dichotomous variable. With regard to inpatient admissions for asthma during the baseline year, the results from the HES database and CPRD were recorded and analyzed separately. However, in the final multivariable model for this subset, only inpatient admissions recorded in CPRD were used so that the ORs reflect the likelihood of hospital inpatient admission for asthma (as recorded in the HES system) using data from primary-care medical records (as recorded in CPRD).

\section{Results}

\section{Baseline characteristics}

Of 343,927 patients identified with asthma and no other chronic respiratory diseases, 220,960 patients had valid blood eosinophil counts recorded during the study period, and 130,547 patients met the full study criteria (Figure 1). Key baseline characteristics are summarized in Tables 2 and 3; complete baseline data are provided in Tables S2 and S3. Mean age was 49 years, $66 \%$ of patients were female, $67 \%$ were either overweight $(27 \%)$ or obese $(40 \%), 44 \%$ were current $(19 \%)$ or former (25\%) smokers, and $44 \%$ had comorbid rhinitis. Mean PEF was $84 \%$ of predicted normal. The median blood eosinophil count was $200 / \mu \mathrm{L} ; 16 \%$ of patients had a count $>400 / \mu \mathrm{L}$. Most patients were being managed at treatment step 2 (41\%) or above (37\%). Asthma-related A\&E attendance or inpatient admission was reported in $0.6 \%$ of patients, and $19 \%$ of patients had one or more acute OCS courses.

\section{Exacerbation rates}

Approximately $7 \%$ of patients had two or more exacerbations in either their baseline $(6.9 \%)$ or outcome $(6.5 \%)$ year.
Table 2 Key baseline patient characteristics: demographic and clinical indices

\begin{tabular}{|c|c|}
\hline Variable & $\mathbf{N}(\%)^{a}$ \\
\hline Total patients & $130,547(100)$ \\
\hline Age (years), mean (SD) & $48.8(17.4)$ \\
\hline Gender, female & $86,039(65.9)$ \\
\hline BMI $\left(\mathrm{kg} / \mathrm{m}^{2}\right)$, mean $(\mathrm{SD})$ & $28.5(6.5)$ \\
\hline Underweight & $3,934(3.2)$ \\
\hline Normal & $36,394(29.6)$ \\
\hline Overweight & $33,446(27.2)$ \\
\hline Obese & $49,108(40.0)$ \\
\hline \multicolumn{2}{|l|}{ Smoking status } \\
\hline Nonsmoker & $72,552(55.7)$ \\
\hline Smoker & $24,443(18.8)$ \\
\hline Ex-smoker & $33,253(25.5)$ \\
\hline$\%$ predicted PEF & $105,515(80.8)^{b}$ \\
\hline Mean (SD) & $83.9(20.0)$ \\
\hline Blood eosinophils $(/ \mu \mathrm{L})$, median (IQR) & $200(120,350)$ \\
\hline$>400$ & $20,999(16.1)$ \\
\hline \multicolumn{2}{|l|}{ Comorbidities } \\
\hline Anaphylaxis, history & $735(0.6)$ \\
\hline Anxiety/depression & $51,047(39.1)$ \\
\hline Diabetes & $32,433(24.8)$ \\
\hline Eczema & $42,166(32.3)$ \\
\hline GERD & $19,114(14.6)$ \\
\hline Heart failure & $4,172(3.2)$ \\
\hline Ischemic heart disease & $7,815(6.0)$ \\
\hline Psoriasis & $6,133(4.7)$ \\
\hline Rhinitis & $57,655(44.2)$ \\
\hline \multicolumn{2}{|l|}{ Comedications, prescription for } \\
\hline Acetaminophen & $42,512(32.6)$ \\
\hline NSAIDs & 44,4 II (34.0) \\
\hline
\end{tabular}

Notes: aExcept where noted; bonly $80.8 \%$ of patients had PEF data.

Abbreviations: BMI, body mass index; GERD, gastroesophageal reflux disease; IQR, interquartile range; NSAIDs, nonsteroidal anti-inflammatory drugs; PEF, peak expiratory flow, expressed as percentage of predicted normal; SD, standard deviation.

Of the 9,009 patients who had two or more exacerbations during their baseline year, 3,681 (41\%) patients had two or more exacerbations the following year. Of the 121,538 patients who had no exacerbation or only one exacerbation in their baseline year, 4,748 (4\%) patients had two or more exacerbations the following year (Table S3).

\section{Exacerbation predictors}

The variables that were predictive $(P<0.05)$ of two or more exacerbations in the full multivariable model are shown in Figure 2, along with their ORs, 95\% CI, and $P$-values. (Univariable results are provided in Tables S4 and S5.) Overall, the likelihood of two or more exacerbations in the outcome year was highest in patients prescribed one or more acute OCS courses in the baseline year (Figure 2B). Of the demographic and clinical variables, having a blood eosinophil count $>400 / \mu \mathrm{L}$ was the strongest predictor of two or more exacerbations (Figure 2A). 
Table 3 Key baseline patient characteristics: asthma treatment and control

\begin{tabular}{|c|c|}
\hline Variable & $\mathbf{N}(\%)^{a}$ \\
\hline \multicolumn{2}{|l|}{ Treatment step } \\
\hline 0 & I3,654 (10.5) \\
\hline I & $|4,95|(\mid 1.5)$ \\
\hline 2 & $53,964(4 \mid .3)$ \\
\hline 3 & $17,655(13.5)$ \\
\hline 4 & $29,243(22.4)$ \\
\hline 5 & $\mathrm{I}, 080(0.8)$ \\
\hline \multicolumn{2}{|c|}{ Average SABA dosage ( $\mu g /$ day) (salbutamol equivalent) } \\
\hline Median (IQR) & $164.4(55,384)$ \\
\hline 0 & $25,37 \mid(19.4)$ \\
\hline $\mathrm{I}-200$ & $44,780(34.3)$ \\
\hline $20 I-400$ & $29,778(22.8)$ \\
\hline$>400$ & $30,618(23.5)$ \\
\hline \multicolumn{2}{|c|}{ Average ICS dosage ( $\mu \mathrm{g} /$ day) (FP equivalent) } \\
\hline Median (IQR) & $219.2(55,570)$ \\
\hline 0 & $29,222(22.4)$ \\
\hline $\mathrm{I}-200$ & $29,198(22.4)$ \\
\hline $20 I-400$ & $26,045(20.0)$ \\
\hline $40 I-800$ & $24,440(18.7)$ \\
\hline$>800$ & $21,642(16.6)$ \\
\hline \multicolumn{2}{|c|}{ GP consults for LRTI } \\
\hline Median (IQR) & $0(0,0)$ \\
\hline 0 & $109,725(84.1)$ \\
\hline I & I5,508 (II.9) \\
\hline $2+$ & $5,314(4.1 \%)$ \\
\hline \multicolumn{2}{|c|}{ Acute OCS courses } \\
\hline Median (IQR) & $0(0,0)$ \\
\hline 0 & $105,963(8 \mid .2)$ \\
\hline I & $|4,2| 4(10.9)$ \\
\hline 2 & $4,901(3.8)$ \\
\hline $3+$ & $5,469(4.2)$ \\
\hline \multicolumn{2}{|c|}{ Hospital attendance/admission, at least one asthma-related } \\
\hline$A \& E$ & $333(0.3)$ \\
\hline Inpatient & $455(0.3)$ \\
\hline Outpatient & $4,644(3.6)$ \\
\hline \multicolumn{2}{|l|}{ Exacerbations } \\
\hline $0 / 1$ & $121,538(93.1)$ \\
\hline $2+$ & $9,009(6.9)$ \\
\hline
\end{tabular}

Notes: aExcept where noted.

Abbreviations: A\&E, accident and emergency department; FP, fluticasone propionate; GP, general practitioner; ICS, inhaled corticosteroid; IQR, interquartile range; LRTI, lower respiratory tract infection; OCS, oral corticosteroid; SABA, short-acting $\beta_{2}$ agonist.

Treatment step and average daily SABA and ICS dosages were found to be collinear, so only treatment step was used in the main multivariable model. When SABA or ICS dosage was used in place of treatment step (Figure 2C), average daily SABA and ICS dosages significantly influenced the likelihood of two or more exacerbations in a bidirectional pattern: compared with no usage, low-to-moderate dosages (1-400 $\mu \mathrm{g} /$ day $)$ significantly decreased the odds, and high dosages $(>400 \mu \mathrm{g} /$ day SABA [salbutamol equivalent] and $>800 \mu \mathrm{g} /$ day ICS [FP equivalent]) significantly increased the odds of having two or more exacerbations in the next year. This pattern is consistent with that of treatment step (Figure 2B): compared with patients at step 2 (daily controller medication), those on no treatment (step 0) or only SABA as needed (step 1) were significantly more likely to have two or more exacerbations, as were those prescribed more intensive controller regimens (steps 3-5).

In the multivariable model that excluded the patients with no baseline PEF data, the likelihood of having two or more exacerbations in the next year decreased a small but significant amount for every $1 \%$ increase in percent predicted PEF (OR: 0.990 [95\% CI: $0.989,0.992]$; $P<0.001$ ). The results for this dataset were otherwise comparable with those of the full study population (data available upon request).

\section{Hospitalization predictors}

The HES subset comprised 47,718 patients (37\% of the full study population). Patient characteristics were similar to those of the full study group, except for inpatient admissions for asthma, which, as expected, were higher in the HES subset $(1.2 \%)$ than in the full study group $(0.3 \%)$, thus validating the inclusion of the HES subset. (Baseline data for these patients are provided in Tables $\mathrm{S} 6$ and $\mathrm{S} 7$, and univariable results in Tables S8 and S9).

The variables that were predictive $(P<0.05)$ of at least one hospitalization for asthma in the next year are shown in Figure 3. Of note, hospitalization for asthma in the baseline year (as documented in the patient's primary-care record) was the best predictor of hospitalization for asthma in the outcome year (as documented in the HES system). That is, even though the clinical practice database missed $76 \%$ of the HES inpatient admissions for asthma (Table S7), these primary-care data were still strongly predictive of hospitalization for asthma in the next year.

\section{Discussion}

This study was designed to investigate the specific components that contribute to a patient's risk for frequent exacerbations of asthma, using data found in routine medical records. Our multivariable analyses yielded $>20$ different exacerbation predictors, all of which are either readily available in UK patients' electronic medical records (eg, age, gender, medications prescribed) or easily obtained in general practice (eg, body mass index [BMI], blood eosinophil count, percent predicted PEF). Not only does this list complement and expand upon the current GINA 
A

Age, per year increas

Gender, female versus male

Overweight versus normal BMI

Obese versus normal BMI

Smoker versus nonsmoker

Ex-smoker versus nonsmoker

Blood eosin $>400 / \mu \mathrm{L}$ versus $\leq 400 / \mu \mathrm{L}$

Anxiety/depression

Diabetes (type I or II)

Eczema

GERD

Rhinitis

Acetaminophen script*
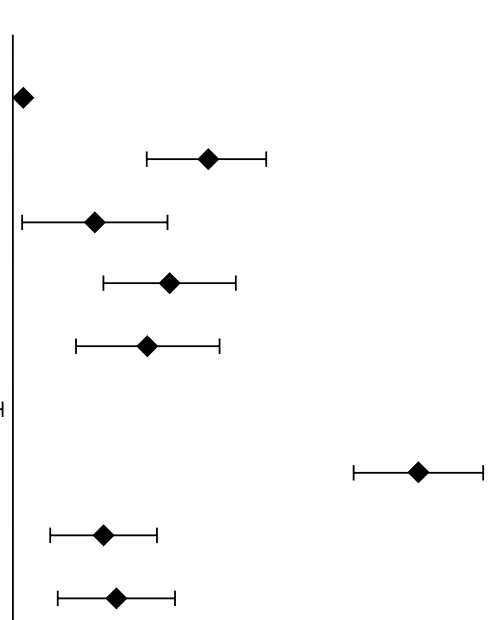

$\longmapsto$

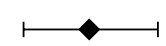

$\longmapsto$

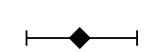

Odds ratio $(95 \% \mathrm{Cl}) \quad P$-value

$1.007(1.005,1.008)<0.001$

$1.21(1.14,1.28) \quad<0.001$

$1.08(1.01,1.16) \quad 0.028$

$1.17(1.09,1.24)<0.001$

$1.14(1.06,1.22)<0.001$

$0.93(0.88,0.99) \quad 0.024$

$1.48(1.39,1.58) \quad<0.001$

$1.09(1.04,1.15) \quad 0.001$

$1.11(1.05,1.17)<0.001$

$1.08(1.03,1.14) \quad 0.003$

$1.12(1.05,1.20) \quad 0.001$

$1.10(1.04,1.16)<0.001$

$1.23(1.17,1.30)<0.001$

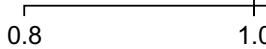

Odds ratios $(95 \% \mathrm{Cl})$

B

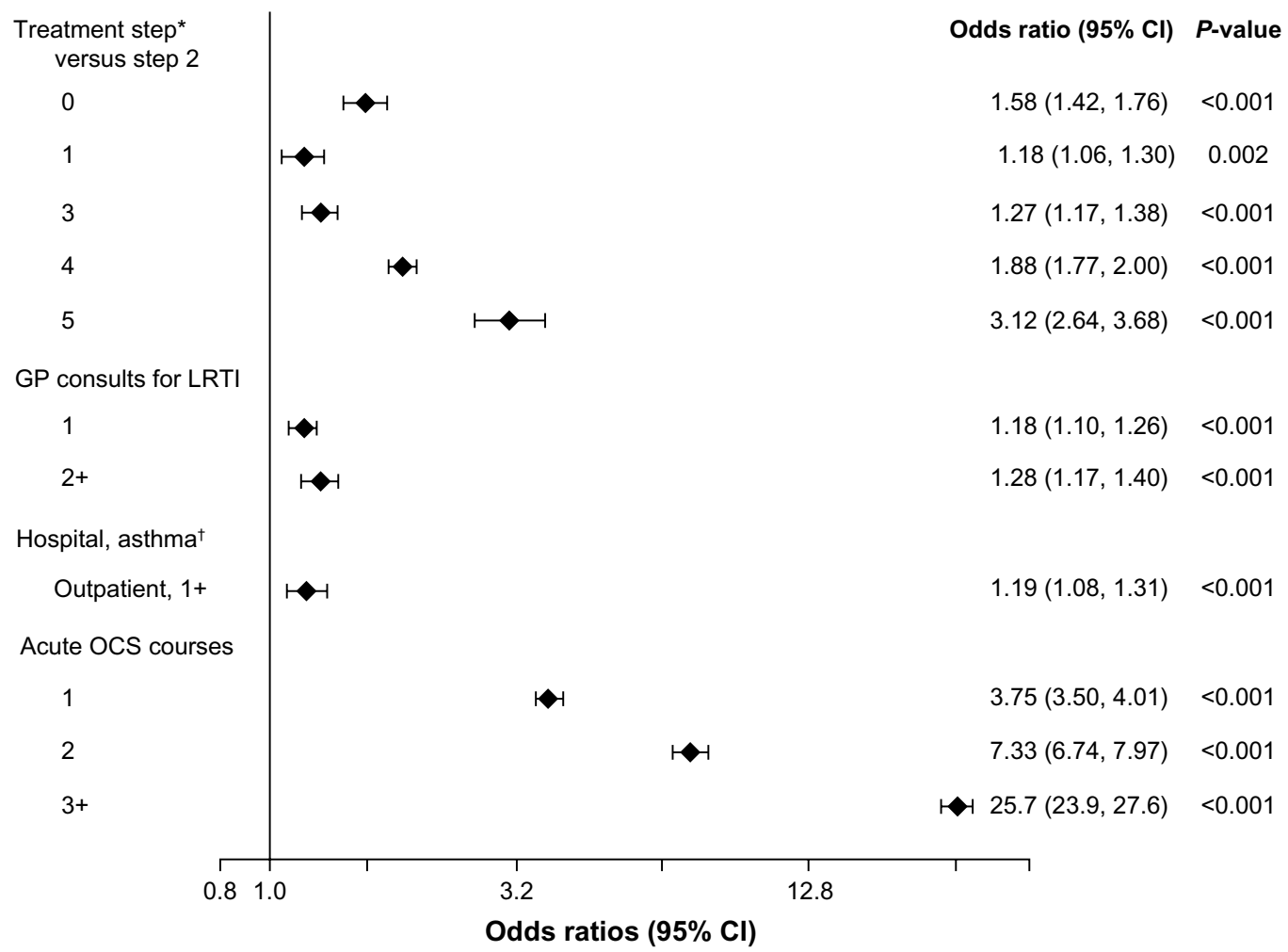

Figure 2 (Continued) 


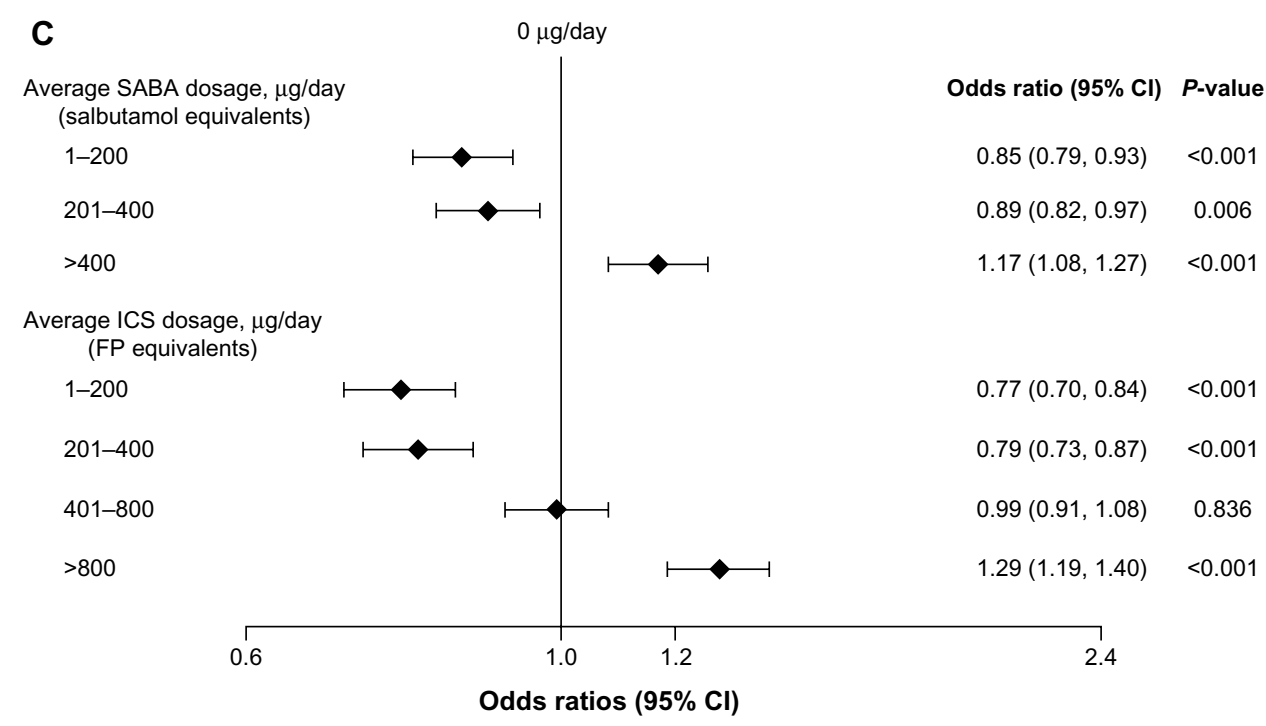

Figure 2 Odds of two or more exacerbations (versus 0 or I) in the next year.

Notes: (A) Demographic and clinical indices; (this multivariable model also includes the predictors shown in B). *Prescription for nonsteroidal anti-inflammatory drugs was interchangeable with acetaminophen prescription and similarly increased the likelihood of two or more exacerbations in the next year (odds ratio: I. 12 [95\% Cl: I.06, I.18]; $P<0.00$ I). (B) Asthma treatment and control; (this multivariable model also includes the predictors shown in $\mathbf{A}$ ). ${ }^{\dagger}$ Hospital, asthma indicates asthma-related hospital attendance/admission (here, at least one outpatient attendance) during the baseline year. *Treatment step was interchangeable with average daily short-acting $\beta 2$ agonist or inhaled corticosteroid dosage. (C) Average daily SABA and ICS dosages when these variables replaced treatment step in the multivariable model. Reference category for each variable is none $(0 \mu \mathrm{g} /$ day $)$.

Abbreviations: Blood eosin, blood eosinophil count; BMI, body mass index; Cl, confidence interval; FP, fluticasone propionate; GERD, gastroesophageal reflux disease; GP, general practitioner; ICS, inhaled corticosteroid; LRTI, lower respiratory tract infection; OCS, oral corticosteroid; SABA short-acting $\beta 2$ agonist.

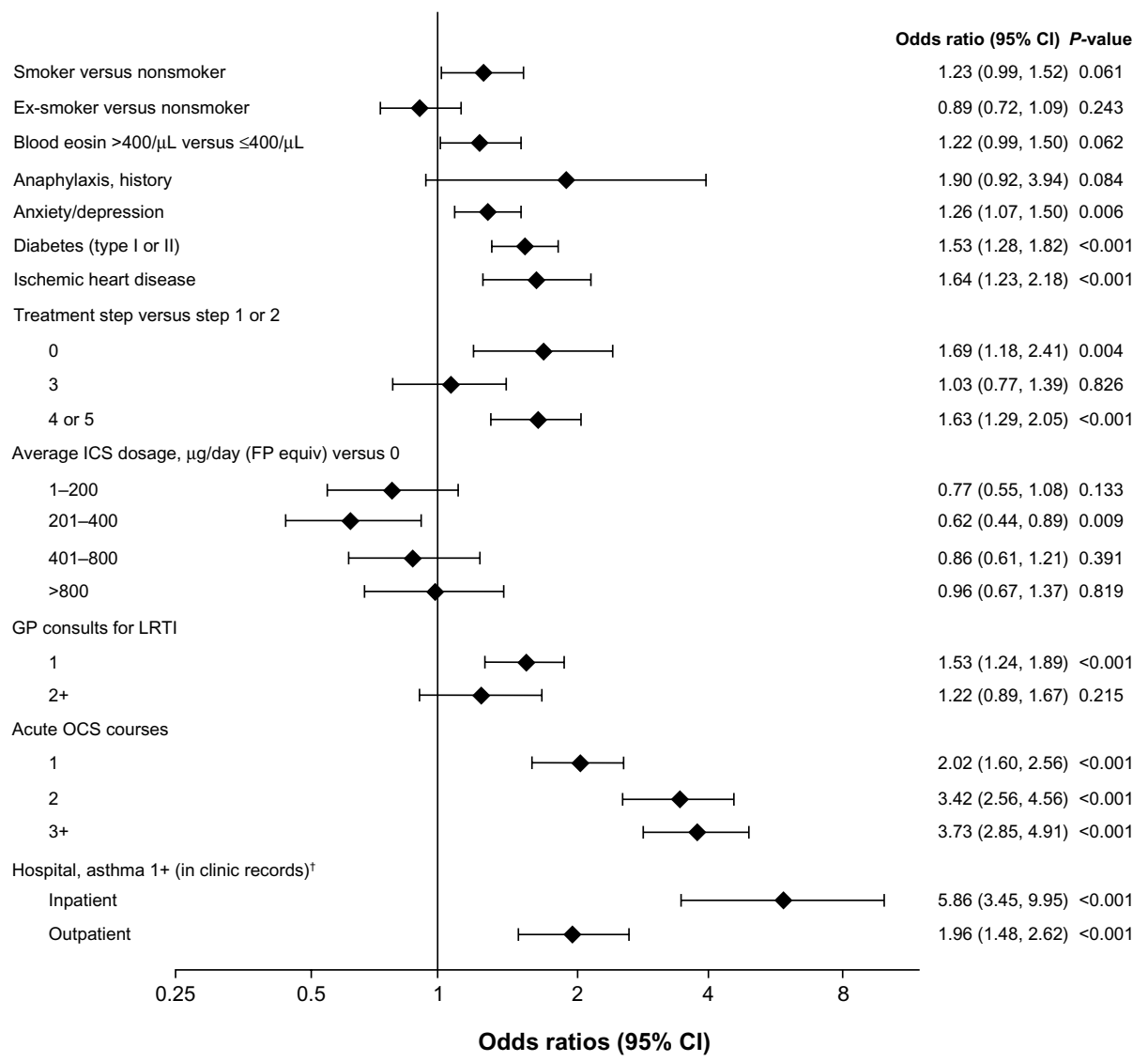

Figure 3 HES subset: odds of at least one inpatient admission for asthma (versus 0 ) in the next year.

Notes: The HES subset comprised 47,718 patients ( $37 \%$ of the full study group). tHospital, asthma I+, at least one asthma-related hospital attendance/admission during the baseline year (data from clinic records).

Abbreviations: Blood eosin, blood eosinophil count; Cl, confidence interval; equiv, equivalents; FP, fluticasone propionate; GP, general practitioner; HES, Hospital Episode Statistics; ICS, inhaled corticosteroid; LRTI, lower respiratory tract infection; OCS, oral corticosteroid. 
recommendations, ${ }^{6}$ it is focused specifically on patients at risk for frequent exacerbations, and it is derived from a heterogeneous population of $>130,500$ asthma patients. Our study population included teenagers and young adults, elderly patients, smokers, patients with significant comorbidities and concomitant medications, and every level of asthma severity, treatment intensity, and symptom control.

\section{Study limitations}

Our study design was intended to be inclusive and representative of real-life asthma care, but we acknowledge that our study population does not perfectly represent the general UK asthma population. First, we excluded patients with other chronic respiratory diseases, such as chronic obstructive pulmonary disease (COPD). Asthma-COPD overlap syndrome (ACOS) reportedly occurs in $15 \%$ to $20 \%$ of asthma patients, and in some populations the incidence may be even higher. ${ }^{6}$ Patients with features of both diseases often experience frequent respiratory exacerbations, ${ }^{23}$ so a similar study is warranted in patients with both asthma and COPD. It is possible, perhaps even likely, that ACOS carries its own unique profile of exacerbation predictors.

Second, in order to determine the predictive value of blood eosinophil count, we excluded patients who did not have a numerical blood eosinophil count, so our study inevitably selected for asthma patients whose physicians had performed at least a white cell differential for some reason. It was not possible to determine the reasons why physicians conducted white blood cell counts in these patients. However, even in this population, only $16 \%$ of patients had systemic eosinophilia $(>400 / \mu \mathrm{L})$. Similar or higher rates of systemic eosinophilia (18\% to $26 \%$ ) are reported in adults with asthma, ${ }^{12,17,18}$ so our selection of patients with blood eosinophil counts does not appear to have selected particularly for patients with systemic eosinophilia. That said, a broader exacerbation risk study is nearing completion that is not limited to patients with blood eosinophil data and which examines the risks for multiple exacerbations over a 2-year outcome period in patients with active asthma (two or more asthma prescriptions during their baseline year).

Third, we did not include blood neutrophil count as an a priori variable, as we were focused on the predictive value of blood eosinophil count. In a recent study of adult-onset asthma, increased blood neutrophil count was associated with disease severity, ${ }^{24}$ so blood neutrophil count would be a worthwhile addition in future exacerbation risk studies of this type.

Lastly, ours was an observational study using historical data. The subtext of our hypothesis was that the modifiable and manageable risk factors thus identified may be targeted by primary-care physicians to reduce the patient's risk of having multiple severe exacerbations in the next year. However, an interventional study using either a matched case-control or crossover design would be needed to show that exacerbations are prevented or reduced in frequency through such targeted interventions.

\section{Key findings}

Several of the exacerbation predictors identified in our study have been previously reported as significantly increasing the risk for frequent exacerbations. However, there are three findings of particular note in our study.

1. "Frequent exacerbators" are a labile, and potentially modifiable, group. Having even one exacerbation in the baseline year, as represented by acute OCS use in the full study group, was the single best predictor of multiple exacerbations in the outcome year, and the likelihood increased further with each additional baseline exacerbation (Figure 2B). Even so, only $41 \%$ of the patients who had multiple exacerbations in their baseline year also had multiple exacerbations in the following year; the remaining $59 \%$ had no exacerbations $(31 \%)$ or only one $(28 \%$; Table S3). Thus, "frequent exacerbator" appears to be a more labile - and potentially more modifiable - state than is implied by studies aimed at characterizing it as a specific asthma phenotype.

2. Several novel exacerbation predictors were identified in routine medical records. Our study identified a number of novel predictors of frequent exacerbations, including some comorbidities and comedications not always considered in asthma management: age, increased risk per year; female gender; being overweight or obese (separate risks); comorbid diabetes (type I or II), eczema, or rhinitis; prescription for acetaminophen or an NSAID; antibiotic prescription for lower respiratory tract infection (LRTI); and no SABA or ICS use. When the outcome measure was hospitalization for asthma (Figure 3), comorbid ischemic heart disease was another novel exacerbation predictor.

The following factors significantly decreased the likelihood of multiple exacerbations: being an ex-smoker (versus nonsmoker); every $1 \%$ increase in percent predicted PEF; and low-to-moderate SABA/ICS usage (1-400 $\mu \mathrm{g} /$ day versus none). The apparently lower risk for ex-smokers may be explained by the confounding influences of age and acute OCS use. Ex-smokers were older than smokers and nonsmokers, and they had more acute OCS courses, so adjusting for age and acute OCS use in the multivariable model decreased their OR in 
relation to nonsmokers. More importantly, being a current smoker significantly increased the likelihood of multiple exacerbations. Average daily SABA and ICS dosages represent the number of refilled prescriptions in the year of interest (Table S1), so the lower odds of multiple exacerbations associated with reliever and controller use is also noteworthy, given that lack of adherence to asthma prescriptions is relatively common and it contributes to poor current control and increases future risk. ${ }^{25}$

Although elevated blood eosinophil count $(>400 / \mu \mathrm{L})$ is not a novel exacerbation predictor, it was the single best predictor of multiple exacerbations among all of the demographic and clinical indices examined. Previous studies suggest that systemic eosinophilia may be associated with relative resistance to ICS and thus with a greater need for systemic therapy, such as OCS or one of the monoclonal antibody therapies directed at the interleukins involved in eosinophil signaling. ${ }^{15,19-21}$ That may explain why systemic eosinophilia significantly increased the likelihood of multiple exacerbations, which were mostly represented by acute OCS use, in our study. Even though only $16 \%$ of the patients had systemic eosinophilia, its influence as a risk factor for multiple exacerbations and its possible association with a need for systemic therapy make a compelling case for the routine use of blood eosinophil counts in the monitoring and managing of patients with asthma.

3. This multivariable model enables the physician to tailor exacerbation risk management for the individual patient. Although the exacerbation risk associated with most of the factors identified was relatively low, each contributes to a complete picture of the patient's respiratory and systemic state as it relates to the risk for frequent exacerbations. These various predictors may be used by physicians to build a profile of the factors that contribute to an individual patient's exacerbation risk, some of which are modifiable or manageable. The modifiable/manageable risk factors applicable to that patient, such as obesity, smoking habit, specific comorbidities, and asthma drugs or dosages, may then be targeted in the asthma management plan.

We are planning an algorithm that allows the physician to calculate the patient's specific exacerbation risk when several different factors are present. In the meantime, multiplying the ORs of all applicable risk factors will approximate the patient's risk for multiple exacerbations in the next year. Calculating the patient's specific exacerbation risk in this way, or simply weighting all of the applicable risk factors in a written assessment and treatment plan, may encourage better self-management than general statements such as "lose weight", "quit smoking", and "use your steroid inhaler every day". In support of this approach, a Cochrane Database systematic review found that written individualized management plans, combined with regular medical reviews, improved health outcomes and reduced asthma-related hospitalizations in adults with asthma. ${ }^{26}$

\section{Conclusion}

In this study, we aimed to identify specific predictors of frequent exacerbations using data obtained solely from routine medical records. More than 20 different variables significantly increased, and in some cases decreased, the likelihood that the patient would experience two or more exacerbations in the next year. They encompassed demographic and clinical variables, such as age, gender, BMI, smoking status, percent predicted PEF, blood eosinophil count, various comorbidities, and comedications, as well as indices of asthma treatment and control, such as treatment step (alternatively, average daily SABA or ICS dosage), antibiotic prescription for LRTI, acute OCS use, and asthma-related hospital attendance/admission.

Some exacerbation risk factors are inexorable or unavoidable (eg, increasing age, gender), but most are either manageable (eg, comorbidities) or modifiable (eg, obesity, smoking). By identifying and quantitating all applicable risk factors, the physician is better equipped to formulate a treatment plan aimed at reducing the patient's specific risk of frequent exacerbations.

\section{Acknowledgments}

We gratefully acknowledge Vicky Thomas (principal statistician and Head of Statistics, Cambridge Research Support, Ltd), Dr Marjan Kerkhof (senior researcher/epidemiologist, Research in Real-Life), Derek Skinner (data analyst, Optimum Patient Care), and Maria Batsiou (statistician, Cambridge Research Support Ltd ) for additional statistical support.

\section{Disclosure}

David Price has board membership with Aerocrine, Almirall, Amgen, AstraZeneca (AZ), Boehringer Ingelheim (BI), Chiesi, Meda, Mundipharma, Napp, Novartis, and Teva Pharmaceuticals (TP); consultancy with Almirall, Amgen, AZ, BI, Chiesi, GlaxoSmithKline (GSK), Meda, Mundipharma, Napp, Novartis, and TP; grants and unrestricted funding for investigator-initiated studies from UK National Health Service, British Lung Foundation, Aerocrine, AKL Ltd, Almirall, AZ, BI, Chiesi, Eli Lilly, GSK, Meda, Merck, 
Mundipharma, Napp, Novartis, Orion, Pfizer, Respiratory Effectiveness Group, Takeda, TP, and Zentiva; payments for lectures/speaking from Almirall, AZ, BI, Chiesi, Cipla, GSK, Kyorin, Meda, Merck, Mundipharma, Novartis, Pfizer, SkyePharma, Takeda, and TP; payment for manuscript preparation from Mundipharma and TP; patents (planned, pending, or issued) from AKL Ltd; payment for the development of educational materials from GSK and Novartis; stock/stock options from AKL Ltd which produces phytopharmaceuticals; owns $80 \%$ of Research in Real-Life and its subsidiary social enterprise Optimum Patient Care; received payment for travel/accommodations/meeting expenses from Aerocrine, BI, Mundipharma, Napp, Novartis, and TP; funding for patient enrollment or completion of research from Almirral, Chiesi, TP, and Zentiva; and peer reviewer for grant committees of the Medical Research Council (2014), Efficacy and Mechanism Evaluation program (2012), and Health Technology Assessment (HTA) (2014).

Neither Michael Thomas nor any member of his close family has any shares in pharmaceutical companies. In the last 3 years, he has received speaker's honoraria for speaking at sponsored meetings or satellite symposia at conferences from the following companies marketing respiratory and allergy products: Aerocrine, AZ, BI, GSK, Merck Sharp \& Dohme (MSD), TP, and Novartis. He has received honoraria for attending advisory panels with Aerocrine, Almirall, AZ, BI, Chiesi, GSK, MSD, and Novartis. He has received sponsorship to attend international scientific meetings from GSK and AZ. He has received funding for research projects from GSK. He is a member of the BTS-SIGN Asthma guideline group and the National Institute for Health and Care Excellence Asthma guideline group.

Andrew M Wilson, Alison Chisholm, Anna Rigazio, Anne Burden, and Christine King declare that they have no financial interests or other conflicts of interest in relation to this study.

\section{References}

1. Reddel HK, Taylor DR, Bateman ED, et al. An official American Thoracic Society/European Respiratory Society statement: asthma control and exacerbations; standardized endpoints for clinical asthma trials and clinical practice. Am J Respir Crit Care Med. 2009;180:59-99.

2. Kupczyk M, ten Brinke A, Sterk PJ, et al. Frequent exacerbators - a distinct phenotype of severe asthma. Clin Exp Allergy. 2014;44: 212-221.

3. Thomson NC, Chaudhuri R. Identification and management of adults with asthma prone to exacerbations: can we do better? BMC Pulm Med. 2008;8:27.

4. Dougherty RH, Fahy JV. Acute exacerbations of asthma: epidemiology, biology and the exacerbation-prone phenotype. Clin Exp Allergy. 2009;39:193-202.
5. Barnes PK, Jonsson B, Klim JB. The costs of asthma. Eur Respir J. 1996;9:36-42.

6. GINA. The Global Strategy for Asthma Management and Prevention. [updated May 19, 2015]. Available from: http://www.ginasthma.org/local/ uploads/files/GINA_Report_2015_May19.pdf. Accessed August 12, 2015.

7. Griswold S, Nordstrom C, Clark S, et al. Asthma exacerbations in North American adults: who are the "frequent fliers" in the emergency department? Chest. 2005;127:1579-1586.

8. Miller MK, Lee JH, Miller DP, et al. Recent asthma exacerbations: a key predictor of future exacerbations. Respir Med. 2007;101:481-489.

9. ten Brinke A, Sterk PJ, Masclee AA, et al. Risk factors of frequent exacerbations in difficult-to-treat asthma. Eur Respir J. 2005;26: 812-818.

10. Koga T, Oshita Y, Kamimura T, et al. Characterization of patients with frequent exacerbation of asthma. Respir Med. 2006;100:273-278.

11. Osborne ML, Pedula KL, O'Hollaren M, et al. Assessing future need for acute care in adult asthmatics: the Profile of Asthma Risk Study: a prospective health maintenance organization-based study. Chest. 2007;132:1151-1161.

12. Tran TN, Khatry DB, Ke X, et al. High blood eosinophil count is associated with more frequent asthma attacks in asthma patients. Ann Allergy Asthma Immunol. 2014;113:19-24.

13. Gibson PG. Inflammatory phenotypes in adult asthma: clinical applications. Clin Respir J. 2009;3:198-206.

14. Petsky HL, Kynaston JA, Turner C, et al. Tailored interventions based on sputum eosinophils versus clinical symptoms for asthma in children and adults. Cochrane Database Syst Rev. 2007;18:CD005603.

15. Wenzel S, Ford L, Pearlman D, et al. Dupilumab in persistent asthma with elevated eosinophil levels. $N$ Engl J Med. 2013;368: 2455-2466.

16. Malinovschi A, Fonseca JA, Jacinto T, et al. Exhaled nitric oxide levels and blood eosinophil counts independently associate with wheeze and asthma events in National Health and Nutrition Examination Survey subjects. J Allergy Clin Immunol. 2013;132:821-827.

17. Schleich FN, Chevremont $A$, Paulus V, et al. Importance of concomitant local and systemic eosinophilia in uncontrolled asthma. Eur Respir J. 2014;44:97-108.

18. Zeiger RS, Schatz M, Li Q, et al. High blood eosinophil count is a risk factor for future asthma exacerbations in adult persistent asthma. J Allergy Clin Immunol Pract. 2014;2:741-750.

19. Price DB, Rigazio A, Campbell JD, et al. Blood eosinophil count and prospective annual asthma disease burden: UK cohort study. Lancet Respir Med. 2015;3:849-858. http://dx.doi.org/10.1016/S22132600(15)00367-7.

20. Castro M, Zangrilli J, Wechsler ME, et al. Reslizumab for inadequately controlled asthma with elevated blood eosinophil counts: results from two multicentre, parallel, double-blind, randomised, placebo-controlled, phase 3 trials. Lancet Respir Med. 2015;3:355-366.

21. Pavord ID, Bafadhel M. Exhaled nitric oxide and blood eosinophilia: independent markers of preventable risk. J Allergy Clin Immunol. 2013;132:828-829.

22. BTS-SIGN. British Guideline on the Management of Asthma. 2008 [updated May 2011]. Available from: http://www.brit-thoracic.org. uk/document-library/clinical-information/asthma/btssign-asthmaguideline-2011/. Accessed March 24, 2013.

23. Hardin M, Cho M, McDonald ML, et al. The clinical and genetic features of COPD-asthma overlap syndrome. Eur Respir J. 2014;44: 341-350.

24. Amelink M, de Groot JC, de Nijs SB, et al. Severe adult-onset asthma: a distinct phenotype. J Allergy Clin Immunol. 2013;132:336-341.

25. Sims EJ, Price D, Haughney J, et al. Current control and future risk in asthma management. Allergy Asthma Immunol Res. 2011;3: 217-225.

26. Gibson PG, Powell H, Coughlan J, et al. Self-management education and regular practitioner review for adults with asthma. Cochrane Database Syst Rev. 2003;(1):CD001117. 
Journal of Asthma and Allergy

Dovepress

\section{Publish your work in this journal}

The Journal of Asthma and Allergy is an international, peer-reviewed open-access journal publishing original research, reports, editorials and commentaries on the following topics: Asthma; Pulmonary physiology; Asthma related clinical health; Clinical immunology and the immunological basis of disease; Pharmacological interventions and

new therapies. Issues of patient safety and quality of care will also be considered. The manuscript management system is completely online and includes a very quick and fair peer-review system, which is all easy to use. Visit http://www.dovepress.com/testimonials.php to read real quotes from published authors.

Submit your manuscript here: http://www.dovepress.com/journal-of-asthma-and-allergy-journal 